\title{
Self-assembled carbon nanoribbons with the heteroatom doping used as ultrafast charging cathodes in zinc-ion hybrid supercapacitors
}

\author{
Yuying Li ${ }^{1}$, Jiajia Huang ${ }^{1 *}$, Liqun Kang ${ }^{2}$, Zhihong Tian ${ }^{3}$, Feili Lai ${ }^{4}$, Dan J.L. Brett ${ }^{2}$, Tianxi Liu ${ }^{5}$ and \\ Guanjie $\mathrm{He}^{2,6^{*}}$
}

\begin{abstract}
Zinc-ion hybrid supercapacitors (ZHSs) are highly desirable for large-scale energy storage applications owing to the merits of high safety, low cost and ultra-long cycle life. The poor rate performance of cathodes, however, severely hinders their application. Herein, aqueous ZHSs with superior performance were fabricated by employing a series of ultrathin carbon nanobelts modified with $\mathrm{B}, \mathrm{N}, \mathrm{O}$ (CPTHB$B x$ ). The heteroatom doping can significantly modify the chemical behaviors of carbon frameworks, which could generate numerous active sites and accelerate the charge transport. The systematic investigation reveals that the $\mathrm{B}-\mathrm{N}$ groups are active species for fast $\mathbf{Z n}$-ion adsorption and desorption. As a result, the best-performed CPTHB-B2 exhibits an excellent electrochemical performance as cathodes in ZHSs, delivering a high specific capacitance of $415.3 \mathrm{~F} \mathrm{~g}^{-1}$ at $0.5 \mathrm{~A} \mathrm{~g}^{-1}$, a record high capacitance retention of $81 \%$ when increasing the current densities from 0.5 to $100 \mathrm{~A} \mathrm{~g}^{-1}$, an outstanding energy

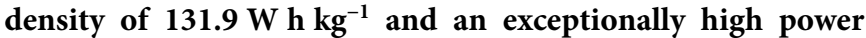
density of $42.1 \mathrm{~kW} \mathrm{~kg}^{-1}$. Our work provides a new cathode design for ultrafast charging $\mathrm{Zn}$-ion storage devices.
\end{abstract}

Keywords: carbon nanoribbons, self-assembled, heteroatom doping, ultrafast charging $\mathrm{Zn}$-ion storage

\section{INTRODUCTION}

Electrochemical energy storage devices, including batteries and supercapacitors, have attracted great attention due to the increasing demands of electronics, electric vehicles and intermittent renewable energies [1-3]. Lithium-ion batteries, featured with high energy density, exhibit safety issues and high fabrication cost owing to the activity of alkali metals and flammable organic electrolytes $[4,5]$. In contrast, zinc-ion electrochemical energy storage devices, including zinc-ion batteries (ZIBs) and hybrid supercapacitors (ZHSs), show a high theoretical capacity of $820 \mathrm{~mA} \mathrm{~h} \mathrm{~g}{ }^{-1}\left(\mathrm{Zn} / \mathrm{Zn}^{2+}\right)$ and low redox potential $(-0.762 \mathrm{~V}$ $v s$. standard hydrogen electrode) of $\mathrm{Zn}$ anodes as well as aqueous electrolytes offering high safety and low cost [6-8]. Currently, the research interest in cathode materials, $\mathrm{Zn}$ anodes and elec- trolytes for ZIBs are increasing dramatically [9-12]. Nevertheless, the dissolution and parasitic reactions of transition metal oxide cathodes can lead to poor cycling stability and limit the wide application of ZIBs [13,14].

Currently, ZHSs, consisting of zinc anodes and porous carbon cathodes, can combine the advantages of secondary batteries and supercapacitors such as high working voltage and ultra-long cycle life, which are recognized as promising candidates for next-generation energy storage devices [8,15]. In 2018, Dong et al. [16] firstly reported aqueous ZHSs using an activated carbon cathode and a $\mathrm{Zn}$ metal anode, and provided new insights for $\mathrm{Zn}$-based energy storage devices. The device delivered a specific capacity of $121 \mathrm{~mA} \mathrm{~h} \mathrm{~g}^{-1}$, a large energy density of $84 \mathrm{~W} \mathrm{~h} \mathrm{~kg}^{-1}$ and power density of $14.9 \mathrm{~kW} \mathrm{~kg}^{-1}$. Recently, although various porous carbon cathodes are designed to enhance the performance of ZHSs, carbon cathodes still suffer from insufficient active sites and sluggish charge transfer processes, further leading to the low capacity and poor rate performance [17-19]. Consequently, the fabrication of carbon materials with abundant active sites and short charge transfer barriers are in urgent need to enhance $\mathrm{Zn}$-ion storage capability of ZHSs cathodes.

It has been demonstrated that introducing heteroatoms into the carbon skeleton is an efficient strategy to solve these issues, which can provide more active sites and enhance the electrical conductivity [20-22]. Besides, the studies on developing suitable active structures and synergy between heteroatoms also need intensive exploration. Herein, we tackle these limitations by introducing heteroatoms $(\mathrm{B}, \mathrm{N}$ and $\mathrm{O}$ ) into ultrathin carbon nanobelts (CPTHB-B $x$ ), which effectively boosts the electrochemical performance for ZHSs. The heteroatoms can not only serve as active sites to enhance $\mathrm{Zn}^{2+}$ adsorption, but also promote the charge transfer rate. Meanwhile, the doping amount of $\mathrm{B}$ atoms was controlled and the $\mathrm{B}-\mathrm{N}$ group was identified as the major active sites as the $\mathrm{Zn}$-ion hosts. As a consequence, the resulting CPTHB-B2 electrode exhibited an excellent specific capacitance of $415.3 \mathrm{~F} \mathrm{~g}^{-1}$ at the current density of $0.5 \mathrm{~A} \mathrm{~g}^{-1}$, one of the highest rate capabilities ( $81 \%$ capacitance retention at $100 \mathrm{~A} \mathrm{~g}^{-1}$ ) and a superb stability (capacitance retention 98.5\%) after 10,000 cycles at a current density of $10.0 \mathrm{~A} \mathrm{~g}^{-1}$. Further-

\footnotetext{
${ }^{1}$ School of Chemical Engineering, Zhengzhou University, Zhengzhou 450001, China

${ }^{2}$ Department of Chemical Engineering, University College London, London WC1E 7JE, UK

${ }^{3}$ Engineering Research Center for Nanomaterials, Henan University, Kaifeng 475001, China

${ }^{4}$ Department of Chemistry, KU Leuven, Celestijnenlaan 200F, Leuven 3001, Belgium

${ }^{5}$ Key Laboratory of Synthetic and Biological Colloids, Ministry of Education, School of Chemical and Material Engineering, International Joint Research Laboratory for Nano Energy Composites, Jiangnan University, Wuxi 214122, China

${ }^{6}$ School of Chemistry, University of Lincoln, Joseph Banks Laboratories, Green Lane, Lincoln, LN6 7DL, UK

* Corresponding authors (emails: huangjiajia@zzu.edu.cn (Huang J); g.he@ucl.ac.uk (He G))
} 
more, an energy density of $131.9 \mathrm{~W} \mathrm{~h} \mathrm{~kg}^{-1}$, together with a remarkable power density of $41.2 \mathrm{~kW} \mathrm{~kg}^{-1}$ were achieved. To demonstrate practical applications, a flexible solid-state pouch cell ZHS based on the CPTHB-B2 cathode was constructed, which delivered a good cycling performance under different bending states.

\section{RESULTS AND DISCUSSION}

The preparation process of CPTHB-B $x$ is illustrated in Fig. 1a. As for the formation of PTHB (Fig. S1), the nitrobenzene can not only serve as the solvent in the following polycondensation process, but also as the reactant after being reduced into aniline. The Fourier transform infrared (FTIR) spectrum of the PTHB (Fig. S2) shows an absorption band at $1100 \mathrm{~cm}^{-1}$ for stretching vibration of $\mathrm{C}-\mathrm{O}-\mathrm{C}$, manifesting the successful synthesis of PTHB [23]. The as-prepared PTHB with $\mathrm{N}, \mathrm{O}$ atoms doping and boric acid $\left(\mathrm{H}_{3} \mathrm{BO}_{3}\right)$ were mixed with specific mass ratios (PTHB: $\left.\mathrm{H}_{3} \mathrm{BO}_{3}=1: x, x=1,2,3,4\right)$. Then, the mixture was carbonized at $800^{\circ} \mathrm{C}$ under argon atmosphere, and the $\mathrm{B}$ atom was further introduced into carbon materials.

The morphologies and microstructures of CPTHB-B $x$ and CPTHB samples were observed by scanning electron microscope (SEM), and the results are displayed in Fig. 1b and Figs S3, S4.
Fig. 1b shows that the CPTHB-B2 exhibits an ultrathin carbon nanobelt structure, and the samples with other ratios show the same morphology (Fig. S3), which is further verified by transmission electron microscopy (TEM) in Fig. 1c. The structures of CPTHB-B $x$ exhibit great similarities with CPTHB (Fig. S4), indicating the structure and morphology of nanobelts are well maintained after the introduction of $\mathrm{B}$ atoms. From the highresolution TEM (HR-TEM) in Fig. 1d, the CPTHB-B2 is governed by disordered nanopores. In addition, the elements of $\mathrm{C}$, $\mathrm{O}, \mathrm{N}$, and $\mathrm{B}$ are well-distributed in the nanobelt structure, as depicted in the SEM mapping images (Fig. 1e and Fig. S5). The thickness of the CPTHB-B2 nanobelt was measured by atomic force microscope (AFM) and the randomly measured carbon nanobelts have a thickness of $\sim 3.5 \mathrm{~nm}$ (Fig. 1f). The ultrathin nanobelt structures shorten the distance of ion mobility, thereby facilitating the charge transfer process.

To investigate the structures of the carbon nanobelts, we conducted X-ray diffraction (XRD) measurements of CPTHB and CPTHB-B $x$. Fig. 2a shows two distinct diffraction peaks at around $25^{\circ}$ and $43^{\circ}$, which are indexed to the (002) and (100) lattice planes of graphite carbon, respectively [24]. The structural features were further measured by Raman spectroscopy. The Raman spectrum (Fig. 2b) shows a D band (representing dis-
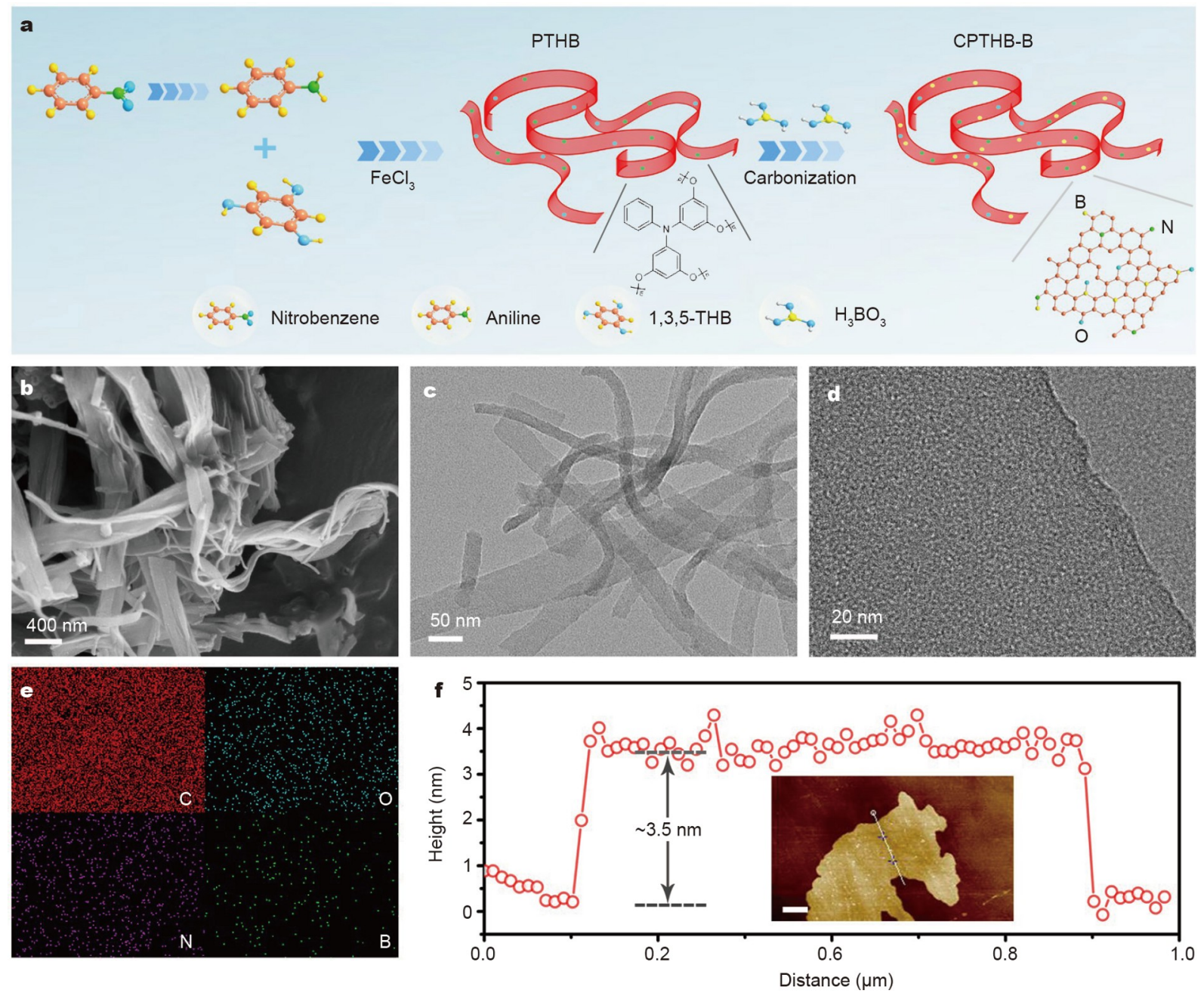

Figure 1 (a) Schematic illustration of the preparation of CPTHB-B. (b) SEM, (c) TEM, (d) HR-TEM and (e) Elemental mapping of CPTHB-B2. (f) AFM and height distribution curve of CPTHB-B2. 

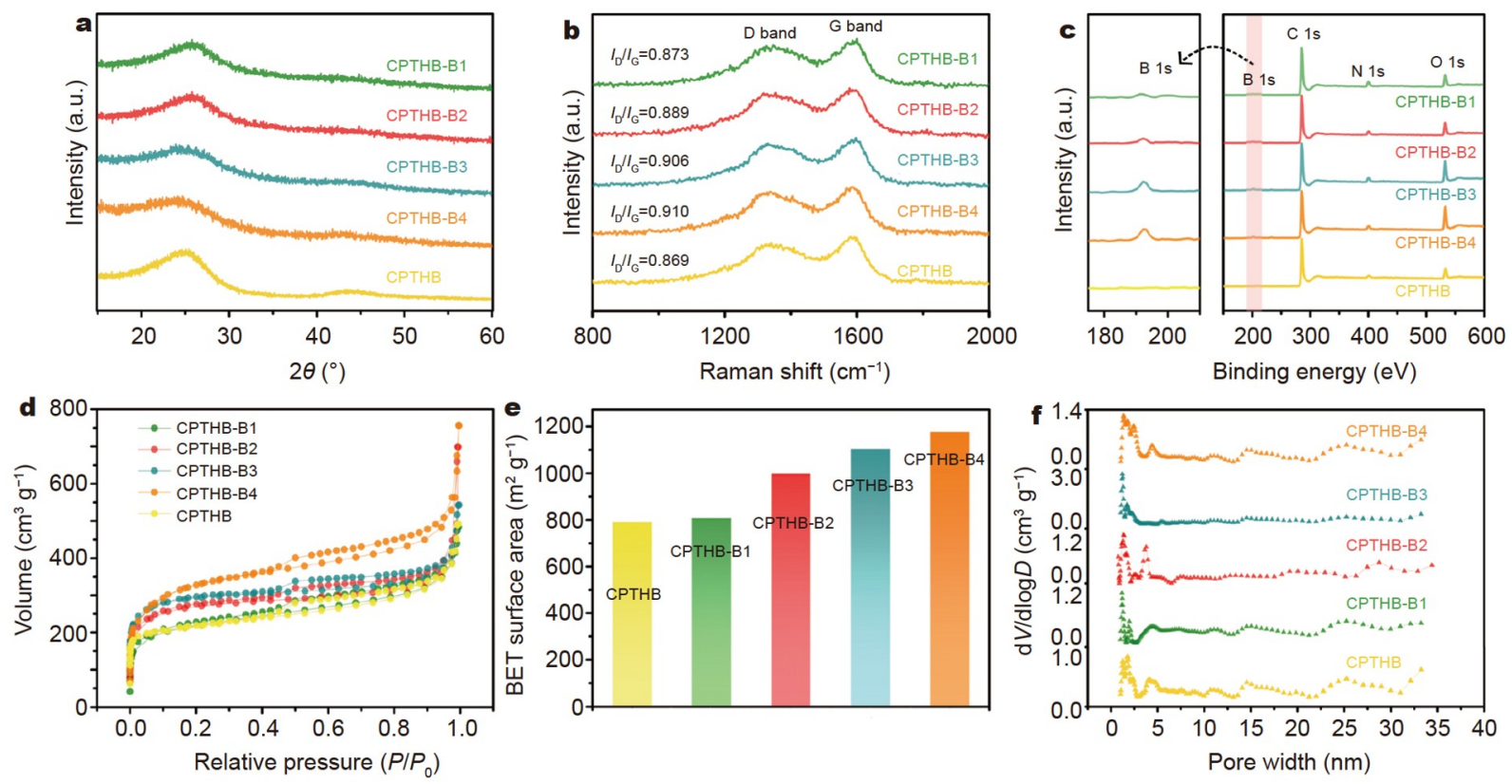

Figure 2 (a) XRD patterns, (b) Raman spectra, (c) XPS survey spectra, (d) nitrogen adsorption-desorption isotherms, (e) BET surface areas and (f) pore size distributions of CPTHB-B $x$ and CPTHB.

ordered carbon) and a G band (representing graphitic carbon) [25]. The peak intensity ratio of the $D$ band to that of the $G$ band $\left(I_{\mathrm{D}} / I_{\mathrm{G}}\right)$ is a useful indicator to evaluate the disorder of carbon materials, and the increasing value (from 0.873 to 0.910 ) indicates that CPTHB-B $x$ possess low graphitic degree and high defect density caused by the B atom doping [25]. Furthermore, the chemical compositions of CPTHB and CPTHB-B $x$ were investigated by X-ray photoelectron spectroscopy (XPS). As shown in Fig. $2 \mathrm{c}$ and Table S1, C $(285.2 \mathrm{eV}), \mathrm{O}(532.2 \mathrm{eV}), \mathrm{N}$ $(400.2 \mathrm{eV}), \mathrm{B}(192.7 \mathrm{eV})$ signals are detected in the survey spectrum, implying the successful doping of B heteroatoms [26]. The nitrogen sorption isotherms in Fig. 2d display the characteristic type I with relatively high adsorbed quantity of $\mathrm{N}_{2}$, indicating the presence of abundant microporous structures. Besides, CPTHB-B $x$ samples exhibit higher amount of adsorbed $\mathrm{N}_{2}$ than CPTHB. Based on the Branauer-Emmett-Teller (BET) method, BET surface areas of CPTHB, CPTHB-B1, CPTHB-B2, CPTHB-B3 and CPTHB-B4 are 791.7, 808.8, 999.2, 1105.3 and $1178.1 \mathrm{~m}^{2} \mathrm{~g}^{-1}$, respectively, which could provide large electrochemically active surface areas for charge storage (Fig. 2e) [27]. The corresponding pore size distribution curves of CPTHB and CPTHB-B $x$ are shown in Fig. $2 \mathrm{f}$, and the porosity of CPTHB-B $x$ is composed of the majority of micropores and few mesopores. The micropores can be regarded as the primary active sites for $\mathrm{Zn}$ ion adsorption and the mesopores, which can accelerate the electrolyte uptake, further increase the density of active sites [28].

As expected, the as-prepared CPTHB-B $x$ samples exhibit an ultrathin nanobelt and heteroatom doped structure, providing sufficient $\mathrm{Zn}$ ion adsorption sites and rapid charge-diffusion rate. Subsequently, the electrochemical activities of the synthesized CPTHB-B $x$ as the cathodes were evaluated in ZHSs with $2 \mathrm{~mol} \mathrm{~L}^{-1} \mathrm{ZnSO}_{4}$ as the electrolyte ( $\mathrm{Zn} / / \mathrm{CPTHB}-\mathrm{B} x$ ), and the device configuration is indicated in Fig. 3a. Owing to the combination of supercapacitor-type cathode and battery-type anode, the store and output energy of ZHSs is via ion adsorption/des- orption on the CPTHB-Bx cathode and reversible deposition/ stripping process on the $\mathrm{Zn}$ anode. Fig. $3 \mathrm{~b}$ shows the cyclic voltammetry $(\mathrm{CV})$ curves of CPTHB and CPTHB-B $x$ electrodes at $20 \mathrm{mV} \mathrm{s}^{-1}$, indicating that these ZHSs are rechargeable and able to work in a wide voltage range of $0.2-1.8 \mathrm{~V}$. The current density of the CPTHB-B2 is the largest among all the samples at the same scan rate, implying that doping $B$ atoms provides enough active sites for charge storage and an optimal doping ratio was realized. In addition, CV curves in Fig. S6 cannot display obvious deformation even at a high scan rate of $100 \mathrm{mV} \mathrm{s}^{-1}$, which reveals the rapid kinetics and highly rechargeable feature. As presented in Fig. 3c, the specific capacitances were measured by galvanostatic charge-discharge (GCD) curves of $\mathrm{Zn} / / \mathrm{CPTHB}-\mathrm{B} x$ and $\mathrm{Zn} / / \mathrm{CPTHB}$ at a current density of $0.5 \mathrm{~A} \mathrm{~g}^{-1}$. The specific capacitances of $\mathrm{Zn} / / \mathrm{CPTHB}-$ B1, Zn//CPTHB-B2, Zn//CPTHB-B3, Zn//CPTHB-B4 and Zn// CPTHB cathodes reach 224.8, 411.5, 313.0, 222.8 and $143.1 \mathrm{~F} \mathrm{~g}^{-1}$, respectively, in agreement with the $\mathrm{CV}$ results. The rate capabilities of $\mathrm{Zn} / / \mathrm{CPTHB}-\mathrm{B} x$ and $\mathrm{Zn} / / \mathrm{CPTHB}$ were tested at different current densities, as shown in Fig. 3d (corresponding GCD curves are shown in Fig. S7). The discharge capacitances of $\mathrm{Zn//CPTHB-B2} \mathrm{are} \mathrm{411.5,} \mathrm{391.1,} \mathrm{382.2,} \mathrm{369.9,} \mathrm{364.0,} 356.9340 .7$ and $320.6 \mathrm{~F} \mathrm{~g}^{-1}$ at current densities of $0.5,1.0,2.0,5.0,10.0,20.0$, 50.0 and $100.0 \mathrm{~A} \mathrm{~g}^{-1}$, respectively, and the capacitance retention is up to $81 \%$ compared with the initial state at current densities from 0.5 to $100 \mathrm{~A} \mathrm{~g}^{-1}$, which is higher than that of $\mathrm{Zn} / / \mathrm{CPTHB}$ (37\%). When the current density returns to $0.5 \mathrm{~A} \mathrm{~g}^{-1}$, a high specific capacitance of $415.3 \mathrm{~F} \mathrm{~g}^{-1}$ can be achieved, suggesting its high reversibility. According to the above results, $\mathrm{Zn} / / \mathrm{CPTHB}-$ B2 demonstrates not only high capacitance, but also excellent rate performance, much better than most of reported carbon cathodes for ZHSs, which is attributed to the heteroatom doping, abundant defects and ultrathin nanobelt structures.

The electrochemical impedance spectroscopy (EIS) spectrum reveals transmission kinetics of ions and the resistance during the charging/discharging process, as shown in Fig. 3e. In the 

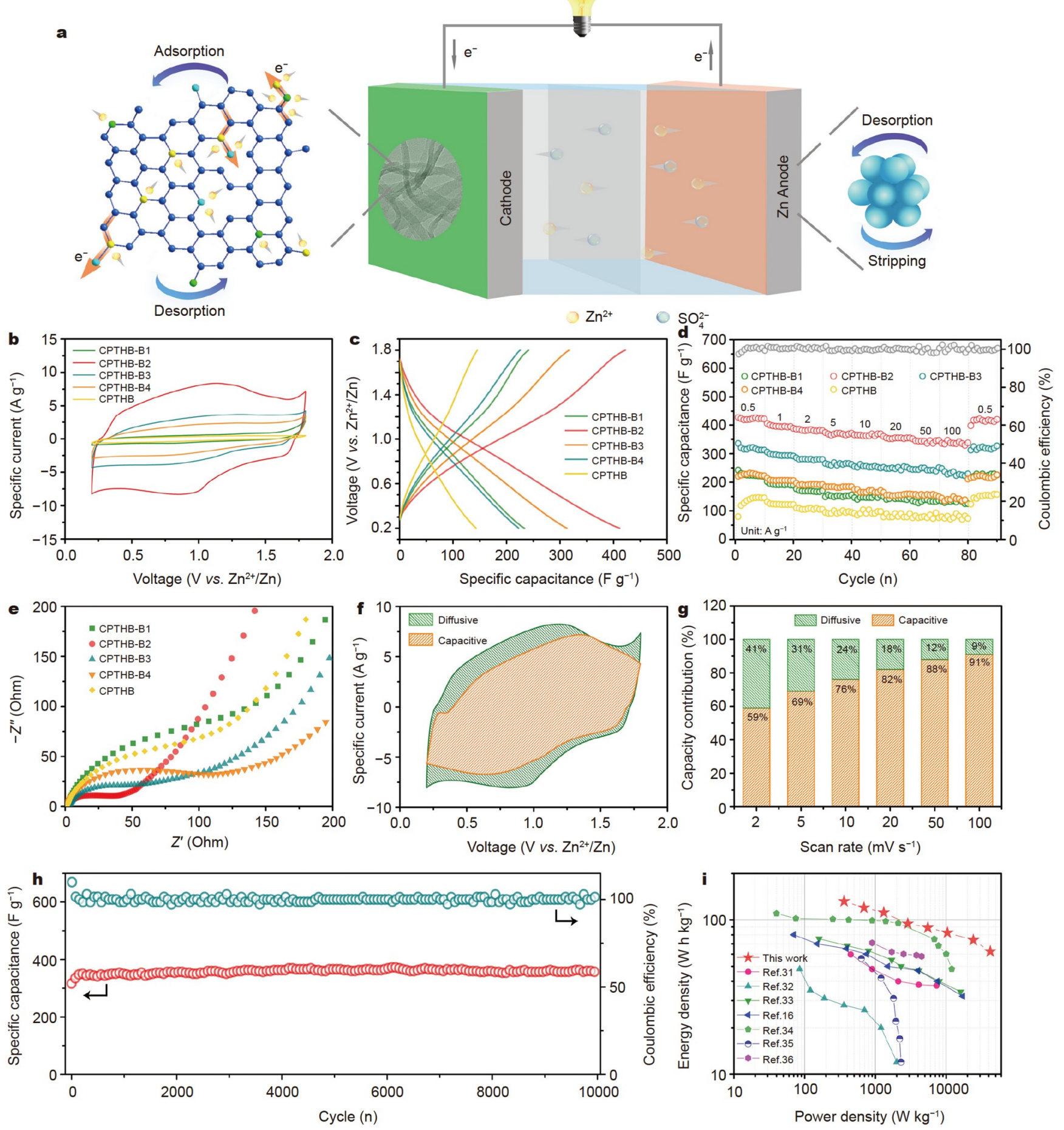

Figure 3 (a) Configuration and working mechanism of the as-fabricated aqueous ZHS. (b) CV curves at $20 \mathrm{mV} \mathrm{s}^{-1}$, (c) GCD curves at $0.5 \mathrm{~A} \mathrm{~g}^{-1}$, (d) rate performances, (e) Nyquist plots of CPTHB-B $x$ and CPTHB. (f) Diffusion and capacitive contribution at $10 \mathrm{mV} \mathrm{s}^{-1}$, (g) normalized capacity contributions at different scan rates, (h) cycling stability at $10 \mathrm{~A} \mathrm{~g}^{-1}$ of CPTHB-B2. (i) Ragone plot of CPTHB-B2-based aqueous ZHS compared with other advanced aqueous ZHSs.

typical Nyquist plots, the semicircle diameters in the high frequency regions represent charge transfer resistance $\left(R_{\mathrm{ct}}\right)$, and the slope in the low frequency regions denotes the $\mathrm{Zn}^{2+}$ diffusion resistance in the electrolyte $\left(R_{\mathrm{s}}\right)$ [29]. The $R_{\mathrm{ct}}$ values from the equivalent circuit model of CPTHB-B1, CPTHB-B2, CPTHB-B3, CPTHB-B4 and CPTHB based ZHSs are about 138, 34, 61, 101 and $104 \Omega$, respectively, demonstrating the fast charge transfer kinetics. To confirm the capacitive effect for the CPTHB-B2 cathode, quantized calculations were carried out based on the $\mathrm{CV}$ curves at different scan rates according to the equations in Supporting information (Equations (S4) and (S5)) [30]. As shown in Fig. 3f, g, the capacitive contribution was calculated to 
be almost $76 \%$ of the total charge storage at $10 \mathrm{mV} \mathrm{s}^{-1}$. Besides, the capacitive contribution increases from $59 \%$ to $91 \%$ with the scan rates increasing from 2 to $100 \mathrm{mV} \mathrm{s}^{-1}$, suggesting the capacitive-dominated charge storage process and relatively fast kinetics under high scan rates. Fig. 3 h and Fig. S8 further show the long cycling performance of the optimized ZHSs, and the $\mathrm{Zn} / / \mathrm{CPTHB}-\mathrm{B} 2$ exhibits outstanding cycling stability with a high capacitance retention (98.5\%) and Coulombic efficiency $(\sim 100 \%)$ after 10,000 charge/discharge cycles at $10 \mathrm{~A} \mathrm{~g}^{-1}$. Such superior capacity and rate capability of the ZHSs are very competitive, better than the majority of other reported carbonbased devices. More encouragingly, the $\mathrm{Zn} / / \mathrm{CPTHB}-\mathrm{B} 2$ device provides an ultrahigh power density of $42.1 \mathrm{~kW} \mathrm{~kg}^{-1}$ at $62.4 \mathrm{~W} \mathrm{~h} \mathrm{~kg}^{-1}$ and a high energy density of $131.9 \mathrm{~W} \mathrm{~h} \mathrm{~kg}^{-1}$ at $361 \mathrm{~W} \mathrm{~kg}^{-1}$ based on the mass of CPTHB-B2. The maximum energy density and power density are better than those of $\mathrm{Zn} / /$ CPTHB-B1 (65.1 W h kg-1, $\left.35.0 \mathrm{~kW} \mathrm{~kg}^{-1}\right), \quad \mathrm{Zn} / /$ CPTHB-B3 (100.4 W h kg $\mathrm{W}^{-1}, 39.9 \mathrm{~kW} \mathrm{~kg}{ }^{-1}$ ), Zn//CPTHB-B4 (69.7 W h kg-1, $32.5 \mathrm{~kW} \mathrm{~kg}^{-1}$ ) and $\mathrm{Zn} / /$ CPTHB (44.7 W h kg-1, $39.3 \mathrm{~kW} \mathrm{~kg}^{-1}$ ) (Fig. S9). As exhibited in the Ragone plots, these values also outperform most of aqueous ZHSs and represent the best power density for all zinc-ion energy storage devices that have been reported so far (Fig. 3i and Table S2) [16,18,28,31-38]. We also compared other types of supercapacitors in Table S3, showing that ZHSs possess both high security and competitive electrochemical performance [39-43]. These inspiring results reveal that the CPTHB-B2 electrode exhibits rapid dynamics during the electrochemical process, more active sites for charge storage and high reversibility, which can be ascribed to its ultrathin ribbon structure, high heteroatom doping level, rich defects, relatively large surface area and wide pore size distribution.
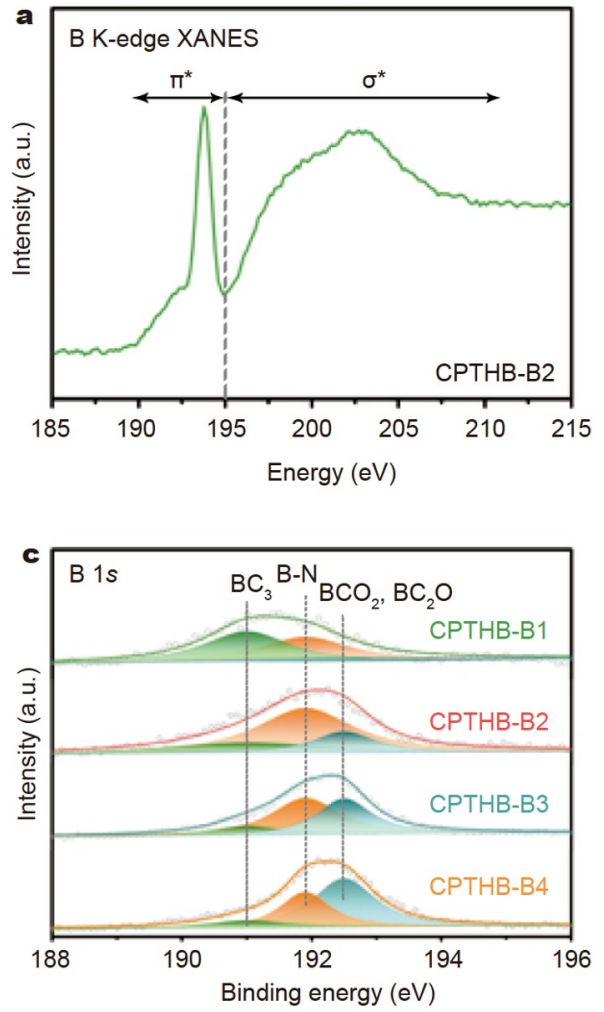

To differentiate active sites for $\mathrm{Zn}$ ion adsorption in $\mathrm{B}, \mathrm{N}, \mathrm{O}$ co-doped carbon materials and investigate the influence of doping amount of $B$, we further studied the chemical states of CPTHB-B $x$ with different ratios of doping B through XPS and $\mathrm{X}$-ray absorption near edge structure (XANES) spectra. Fig. 4a and Fig. S10a show the B K-edge XANES spectrum and peak fitting results of the CPTHB-B2, which can be divided into two regions. The sharp absorption features below $195 \mathrm{eV}$ and the broad absorption peak is above $195 \mathrm{eV}$, corresponding to transition of $\mathrm{B} 1 \mathrm{~s}$ electron to $2 \mathrm{p}_{z} \pi^{*}$ orbitals and to $\sigma^{*}$ orbitals, respectively. In the $\pi^{*}$ transition domain, a sharp absorption peak at $193.8 \mathrm{eV}$ is a characteristic feature of $\mathrm{sp}^{2}$ hybridized trigonal borate species (peak 2). Two additional shoulder peaks are also identified at $191.3 \mathrm{eV}$ (peak 0) and $192.4 \mathrm{eV}$ (peak 1), which are attributed to similar $\mathrm{sp}^{2}$ hybridized trigonal $\mathrm{BC}_{2} \mathrm{O}$ and $\mathrm{BCO}_{2}$ structures, respectively. In the $\sigma^{*}$ transition domain, the broad feature at $196-200 \mathrm{eV}$ origins from trigonal $\mathrm{B}$ species, and the other feature at $200-205 \mathrm{eV}$ is from $\mathrm{sp}^{3}$ hybridized tetrahedral B species [44-46]. This suggests the successful doping of $\mathrm{B}$ atoms into the carbon framework.

Similarly, N K-edge XANES of CPTHB-B2 spectrum and peak fitting results in Fig. $4 \mathrm{~b}$ and Fig. S10b can be divided into two regions, the sharp absorption features below $404 \mathrm{eV}$ with the broad absorption peak above $404 \mathrm{eV}$, corresponding to the transition of $\mathrm{N} 1 \mathrm{~s}$ electron to $2 \mathrm{p}_{z} \pi^{*}$ orbitals and to $\sigma^{*}$ orbitals, respectively. In the $\pi^{*}$ transition region, two sharp peaks at $397.8 \mathrm{eV}$ (peak 1) and $398.9 \mathrm{eV}$ (peak 2) are assigned to pyridinic and pyridone $\mathrm{N}$ species, respectively. The absorption peak at around $400.5 \mathrm{eV}$ (peak 3) is generally recognized as graphitic $\mathrm{N}$ species, and the shoulder peak at about $402.0 \mathrm{eV}$ (peak 4) is possibly associated with oxidized pyridinic $\mathrm{N}$ species. The last
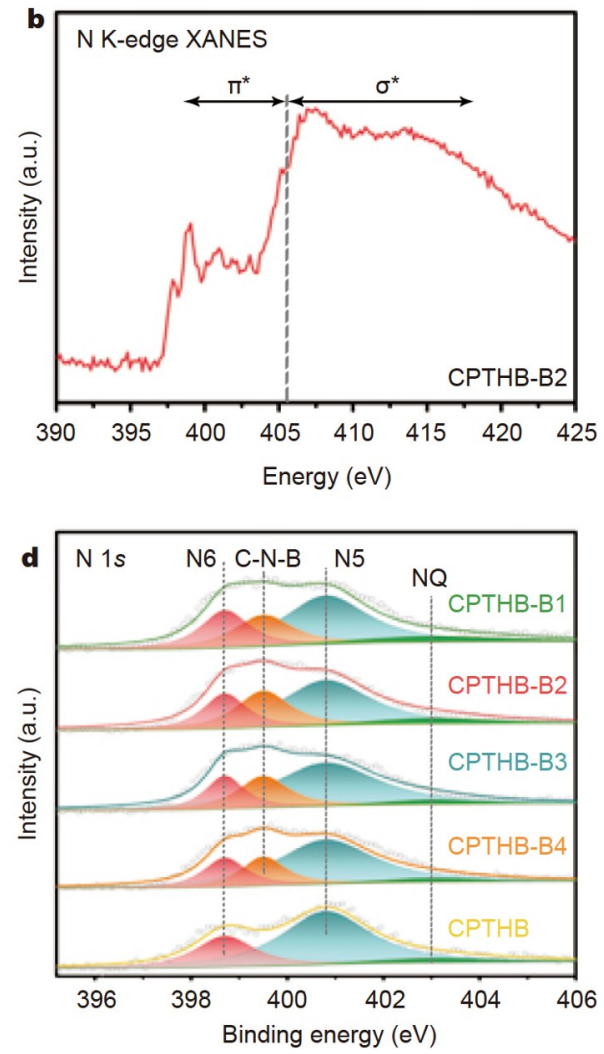

Figure 4 (a) B K-edge XANES spectrum and (b) N K-edge XANES spectrum of CPTHB-B2. (c) B 1s XPS of CPTHB-Bx. (d) N 1s XPS of all samples. 
two peaks at $405.0 \mathrm{eV}$ and $407.0 \mathrm{eV}$ represent the transition to $\sigma^{*}$ orbitals [47-49].

XPS results are displayed in Fig. 4c, d and Fig. S11. The B 1 s spectra (Fig. 4c) reveal the presence of three peaks corresponding to $\mathrm{BC}_{3}$ groups $(191.0 \mathrm{eV}), \mathrm{B}-\mathrm{N}$ groups $(191.9 \mathrm{eV})$ and $\mathrm{BCO}_{2}, \mathrm{BC}_{2} \mathrm{O}$ groups $(192.5 \mathrm{eV}$ ). The $\mathrm{N}$ ls spectra (Fig. $4 \mathrm{~d}$ ) of the samples have been resolved into four individual component peaks representing pyrrolic $\mathrm{N}(\mathrm{N} 6,398.7 \mathrm{eV}), \mathrm{C}-\mathrm{N}-\mathrm{B}$ $(399.5 \mathrm{eV})$, pyridinic $\mathrm{N}(\mathrm{N} 5,400.8 \mathrm{eV})$ and quaternary $\mathrm{N}(\mathrm{NQ}$, $403.0 \mathrm{eV}$ ). The C 1s spectra (Fig. S11a) can be deconvoluted into five peaks, which correspond to $\mathrm{C}-\mathrm{B}$ groups $(284.2 \mathrm{eV}), \mathrm{C} \mathrm{sp}{ }^{2}$ $(284.7 \mathrm{eV}), \mathrm{C}-\mathrm{N}$ groups $(285.3 \mathrm{eV}), \mathrm{C}-\mathrm{O}$ groups $(286.3 \mathrm{eV})$ and $\mathrm{C}=\mathrm{O}$ groups $(288.6 \mathrm{eV})$. The spectra of $\mathrm{O} 1 \mathrm{~s}$ (Fig. S11b) display four characteristic peaks, corresponding to $\mathrm{O}=\mathrm{C}$ groups $(531.4 \mathrm{eV}), \mathrm{O}-\mathrm{C}$ groups $(532.5 \mathrm{eV}), \mathrm{O}-\mathrm{B}$ groups $(533.3 \mathrm{eV})$ and absorbed oxygen $(533.7 \mathrm{eV})$, respectively [26,50,51]. The results confirm that the $\mathrm{B}, \mathrm{N}$ and $\mathrm{O}$ were incorporated into carbon frameworks, which is beneficial to favorable electrochemical performance.

For further investigation, the concentrations of $\mathrm{B}$ species calculated from the corresponding B 1s XPS peaks are presented in Table S4. In comparison with other B doped samples, $\mathrm{CPTHB}-\mathrm{B} 2$ possesses the highest $\mathrm{B}-\mathrm{N}$ content. In the meantime, more $\mathrm{O}$ atoms were introduced owing to the increasing mixed content of $\mathrm{H}_{3} \mathrm{BO}_{3}$, promoting the formation of more $\mathrm{B}-\mathrm{O}$ groups. As mentioned above, it is found that the $\mathrm{B}-\mathrm{N}$ groups are essential to enhance $\mathrm{Zn}$ ion adsorption and electron transport through the carbon. To verify that the active sites for $\mathrm{Zn}$ ion storage in $\mathrm{CPTHB}-\mathrm{B} x$ are $\mathrm{B}-\mathrm{N}$ groups, two additional control experiments were carried out. The CPTHB-N-B with more $\mathrm{N}$ atoms and CTHB-B without $\mathrm{N}$ atoms were prepared and the structural characterizations are presented in Fig. S12 and Table S5. The electrochemical performances of CPTHB-N-B and CTHB-B for ZHSs were evaluated and compared with that of CPTHB-B2. As shown in Figs S13 and S14, Zn//CPTHB-N-B exhibits a remarkable specific capacitance of $449.7 \mathrm{~F} \mathrm{~g}^{-1}$ at the current density of $0.5 \mathrm{~A} \mathrm{~g}^{-1}$ and excellent rate properties with the specific capacitance retention up to $86 \%$ when the current densities increase from 0.5 to $100 \mathrm{~A} \mathrm{~g}^{-1}$, which is higher than that of $\mathrm{Zn} / / \mathrm{CPTHB}-\mathrm{B} 2$ (81\%) under the same testing condition. While the $\mathrm{Zn} / / \mathrm{CTHB}-\mathrm{B}$ shows a much lower specific capacitance of $175.2 \mathrm{~F} \mathrm{~g}^{-1}$ and the capacitance drops to $10.7 \mathrm{~F} \mathrm{~g}^{-1}$ at $20 \mathrm{~A} \mathrm{~g}^{-1}$. These results also verify that $\mathrm{B}-\mathrm{N}$ groups are the main $\mathrm{Zn}$ ion hosts. To investigate the structural change on CPTHB-B2 cathode of ZHS, we characterized XRD and Raman for CPTHBB2 cathodes at different voltages during the charge/discharge process (Fig. S15). The main XRD peaks of the CPTHB-B2 cathode remain unchanged, and the reversible emergence and disappearance of $\mathrm{Zn}_{4} \mathrm{SO}_{4}(\mathrm{OH})_{6} \cdot 4 \mathrm{H}_{2} \mathrm{O}$ peak is observed. Meantime, the ex-situ Raman spectra exhibits the same results, which demonstrates stable structure of the CPTHB-B2 cathodes during the charge storage process $[38,52]$.

The security and flexibility of energy storage device is a demand associated with the development of portable electronic products. To meet this requirement and test the actual energy storage properties of the as-obtained CPTHB-B2 electrode, a flexible solid-state pouch cell ZHS was assembled using CPTHBB2 as the cathode, $\mathrm{Zn}$-deposited carbon cloth as the anode, and solid-state $\mathrm{ZnSO}_{4}$ /polyacrylamide (PAM) gel as the electrolyte and the separator, and then sealed by Al-plastic films under vacuum (Fig. 5a). CV curves of the device shown in Fig. 5b are similar to those of the coin cell system without distortion, indicating the regular operation of the ZHS device, and two devices connected in series can supply a voltage window of $3.4 \mathrm{~V}$. Fig. $5 c$, d further display the electrochemical performance of the flexible solid-state $\mathrm{Zn} / / \mathrm{CPTHB}-\mathrm{B} 2$ pouch cell, which presents an excellent specific capacitance of $245.7 \mathrm{~F} \mathrm{~g}^{-1}$ at $5 \mathrm{~A} \mathrm{~g}^{-1}$. In addition, the solid-state ZHS experienced nearly no capacitance decay under different degrees of bending states. As a demonstration, two Zn//CPTHB-B2 devices connected in series a
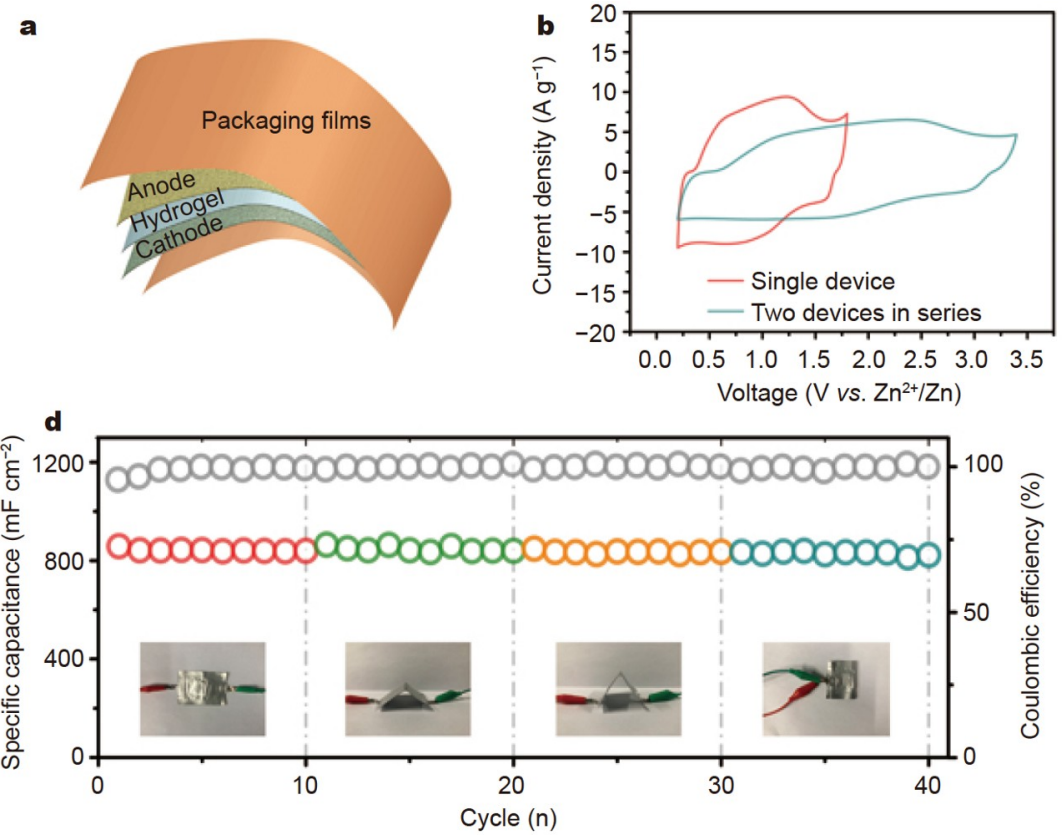
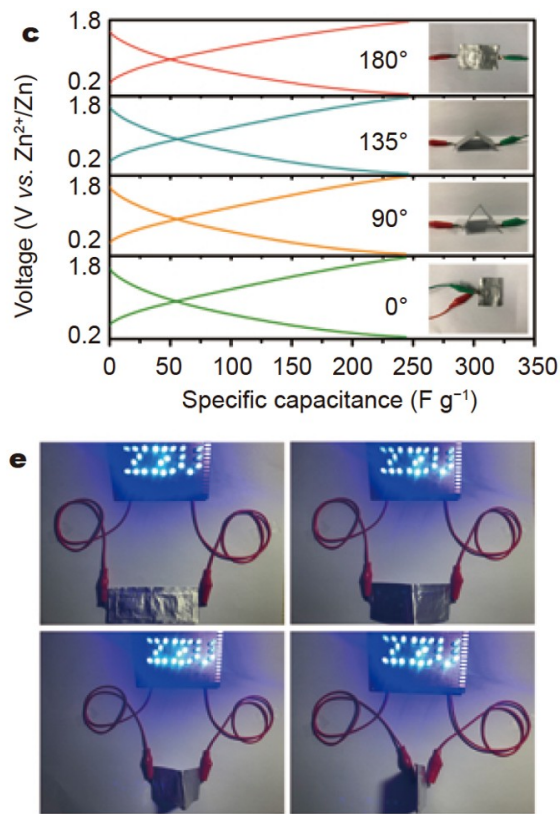

Figure 5 (a) Structural diagram of the flexible solid-state ZHS pouch cell. (b) CV curves of two single devices in series and in parallel at the scan rate of $20 \mathrm{mV} \mathrm{s}^{-1}$. (c) Discharge curves at $5 \mathrm{~A} \mathrm{~g}^{-1}$ under different deformation states, (d) cycling performance at $5 \mathrm{~A} \mathrm{~g}^{-1}$ under different mechanical deformations of the device. (e) Photographs of an LED pattern powered by two devices in series. 
could normally power a series of light-emitting diodes (LEDs) even under bending states, verifying the practical viability of our flexible solid-state ZHSs pouch cells (Fig. 5e).

\section{CONCLUSIONS}

In summary, we synthesized a series of ultrathin carbon nanobelts with $\mathrm{B}, \mathrm{N}, \mathrm{O}$ doping (CPTHB-Bx) as the cathodes for aqueous ZHSs. Owing to more $\mathrm{Zn}$ ion adsorption sites and ultrafast charge-transfer created by the heteroatom doping, the optimized CPTHB-B $x$ electrode displayed substantially impressive rate performance and extraordinary specific capacitance. We have successfully identified that $\mathrm{B}-\mathrm{N}$ group is capable of promoting the $\mathrm{Zn}$ ion adsorption, and acts as the main active site for energy storage. The as-fabricated ZHS with CPTHB-B2 cathode presents an outstanding specific capacitance of $415.3 \mathrm{~F} \mathrm{~g}^{-1}$ at $0.5 \mathrm{~A} \mathrm{~g}^{-1}$, and a considerable capacitance retention of $81 \%$ at the current density of $100 \mathrm{~A} \mathrm{~g}^{-1}$. In addition, a significant energy density of $131.9 \mathrm{~W} \mathrm{~h} \mathrm{~kg}^{-1}$, and a peak power density of $42.1 \mathrm{~kW} \mathrm{~kg}^{-1}$ are afforded. A flexible solid-state ZHS pouch cell was assembled with the CPTHB-B2 electrode, which offers a stable cycling performance under different bending states, and two in series connected devices can power a set of LEDs. Our study can be generally applied for the design of heteroatom-doped carbon electrodes for enhancing energy storage performance in various systems.

\section{Received 4 October 2021; accepted 3 December 2021; published online 29 January 2022}

1 Wang G, Yu M, Feng X. Carbon materials for ion-intercalation involved rechargeable battery technologies. Chem Soc Rev, 2021, 50: 2388-2443

2 Ikram R, Mohamed Jan B, Atif Pervez S, et al. Recent advancements of $\mathrm{N}$-doped graphene for rechargeable batteries: a review. Crystals, 2020, 10: 1080

3 Liu T, Yuan Y, Tao X, et al. Bipolar electrodes for next-generation rechargeable batteries. Adv Sci, 2020, 7: 2001207

4 Fan L, Wei S, Li S, et al. Recent progress of the solid-state electrolytes for high-energy metal-based batteries. Adv Energy Mater, 2018, 8: 1702657

5 Tarascon JM, Armand M. Issues and challenges facing rechargeable lithium batteries. Nature, 2001, 414: 359-367

6 He G, Liu Y, Gray DE, et al. Conductive polymer composites cathodes for rechargeable aqueous $\mathrm{Zn}$-ion batteries: a mini-review. Compos Commun, 2021, 27: 100882

7 Yang F, Shen Y, Cen Z, et al. In situ construction of heterostructured bimetallic sulfide/phosphide with rich interfaces for high-performance aqueous Zn-ion batteries. Sci China Mater, 2022, 65: 356-363

8 Shao Y, Shen F, Shao Y. Recent advances in aqueous zinc-ion hybrid capacitors: a minireview. ChemElectroChem, 2021, 8: 484-491

9 Shan L, Wang Y, Liang S, et al. Interfacial adsorption-insertion mechanism induced by phase boundary toward better aqueous $\mathrm{Zn}$-ion battery. InfoMat, 2021, 3: 1028-1036

10 Zhou X, Lu Y, Zhang Q, et al. Exploring the interfacial chemistry between zinc anodes and aqueous electrolytes via an in situ visualized characterization system. ACS Appl Mater Interfaces, 2020, 12: 5547655482

11 Li C, Xie X, Liu H, et al. Integrated 'all-in-one' strategy to stabilize zinc anodes for high-performance zinc-ion batteries. Natl Sci Rev, 2022, 9: nwab177

12 Li B, Xue J, Han C, et al. A hafnium oxide-coated dendrite-free zinc anode for rechargeable aqueous zinc-ion batteries. J Colloid Interface Sci, 2021, 599: 467-475

13 Guo J, Ming J, Lei Y, et al. Artificial solid electrolyte interphase for suppressing surface reactions and cathode dissolution in aqueous zinc ion batteries. ACS Energy Lett, 2019, 4: 2776-2781

14 Soundharrajan V, Sambandam B, Kim S, et al. The dominant role of $\mathrm{Mn}^{2+}$ additive on the electrochemical reaction in $\mathrm{ZnMn}_{2} \mathrm{O}_{4}$ cathode for aqueous zinc-ion batteries. Energy Storage Mater, 2020, 28: 407-417

15 Liu Y, Lu X, Lai F, et al. Rechargeable aqueous Zn-based energy storage devices. Joule, 2021, 5: 2845-2903

16 Dong L, Ma X, Li Y, et al. Extremely safe, high-rate and ultralong-life zinc-ion hybrid supercapacitors. Energy Storage Mater, 2018, 13: 96102

17 Liu P, Liu W, Huang Y, et al. Mesoporous hollow carbon spheres boosted, integrated high performance aqueous $\mathrm{Zn}$-ion energy storage. Energy Storage Mater, 2020, 25: 858-865

18 Li Z, Chen D, An Y, et al. Flexible and anti-freezing quasi-solid-state zinc ion hybrid supercapacitors based on pencil shavings derived porous carbon. Energy Storage Mater, 2020, 28: 307-314

19 Zhang L, Zhang B, Hu J, et al. An in situ artificial cathode electrolyte interphase strategy for suppressing cathode dissolution in aqueous zinc ion batteries. Small Methods, 2021, 5: 2100094

20 Yuan Y, Chen Z, Yu H, et al. Heteroatom-doped carbon-based materials for lithium and sodium ion batteries. Energy Storage Mater, 2020, 32: $65-90$

21 Kim HT, Shin HO, Jeon IY, et al. Carbon-heteroatom bond formation by an ultrasonic chemical reaction for energy storage systems. Adv Mater, 2017, 29: 1702747

22 Lee YG, An GH. Synergistic effects of phosphorus and boron co-incorporated activated carbon for ultrafast zinc-ion hybrid supercapacitors. ACS Appl Mater Interfaces, 2020, 12: 41342-41349

23 Tian Z, Huang J, Zhang X, et al. Ultra-microporous N-doped carbon from polycondensed framework precursor for $\mathrm{CO}_{2}$ adsorption. Microporous Mesoporous Mater, 2018, 257: 19-26

24 Sevilla M, Fuertes AB. Direct synthesis of highly porous interconnected carbon nanosheets and their application as high-performance supercapacitors. ACS Nano, 2014, 8: 5069-5078

25 Zhang W, Cao Z, Wang W, et al. A site-selective doping strategy of carbon anodes with remarkable K-ion storage capacity. Angew Chem, 2020, 132: 4478-4485

26 Chang Y, Shi H, Yan X, et al. A ternary B, N, P-doped carbon material with suppressed water splitting activity for high-energy aqueous supercapacitors. Curr Alzheimer Resbon, 2020, 170: 127-136

27 Xiang X, Liu E, Li L, et al. Activated carbon prepared from polyaniline base by $\mathrm{K}_{2} \mathrm{CO}_{3}$ activation for application in supercapacitor electrodes. J Solid State Electrochem, 2011, 15: 579-585

28 Pan Z, Lu Z, Xu L, et al. A robust 2D porous carbon nanoflake cathode for high energy-power density $\mathrm{Zn}$-ion hybrid supercapacitor applications. Appl Surf Sci, 2020, 510: 145384

29 Huang J, Li Y, Xie R, et al. Structural engineering of cathodes for improved Zn-ion batteries. J Energy Chem, 2021, 58: 147-155

30 Dong H, Li J, Zhao S, et al. Investigation of a biomass hydrogel electrolyte naturally stabilizing cathodes for zinc-ion batteries. ACS Appl Mater Interfaces, 2021, 13: 745-754

31 Chen S, Ma L, Zhang K, et al. A flexible solid-state zinc ion hybrid supercapacitor based on co-polymer derived hollow carbon spheres. J Mater Chem A, 2019, 7: 7784-7790

32 Cui FZ, Liu Z, Ma DL, et al. Polyarylimide and porphyrin based polymer microspheres for zinc ion hybrid capacitors. Chem Eng J, 2021, 405: 127038

33 Chen S, Yang G, Zhao X, et al. Hollow mesoporous carbon spheres for high performance symmetrical and aqueous zinc-ion hybrid supercapacitor. Front Chem, 2020, 8: 663

34 Dai $\mathrm{X}$, Wan $\mathrm{F}$, Zhang $\mathrm{L}$, et al. Freestanding graphene/VO $\mathrm{VO}_{2}$ composite films for highly stable aqueous $\mathrm{Zn}$-ion batteries with superior rate performance. Energy Storage Mater, 2019, 17: 143-150

35 Wang J, Xie Y, Wang L, et al. Facile synthesis of morphology-controllable $\mathrm{NiCo}_{2} \mathrm{~S}_{4}$ arrays on activated carbon textile as high-performance binder-free supercapacitor electrode. Mater Res Bull, 2020, 131: 110957

36 Tarimo DJ, Oyedotun KO, Mirghni AA, et al. High energy and excellent stability asymmetric supercapacitor derived from sulphur-reduced graphene oxide/manganese dioxide composite and activated 
carbon from peanut shell. Electrochim Acta, 2020, 353: 136498

37

Zheng Y, Zhao W, Jia D, et al. Porous carbon prepared via combustion and acid treatment as flexible zinc-ion capacitor electrode material. Chem Eng J, 2020, 387: 124161

38 Deng X, Li J, Shan Z, et al. A N, O co-doped hierarchical carbon cathode for high-performance $\mathrm{Zn}$-ion hybrid supercapacitors with enhanced pseudocapacitance. J Mater Chem A, 2020, 8: 11617-11625

39 Qin $\mathrm{H}$, Chao H, Zhang M, et al. Precious potential regulation of carbon cathode enabling high-performance lithium-ion capacitors. Curr Alzheimer Resbon, 2021, 180: 110-117

40 Shi X, Yu J, Liu Q, et al. Metal-organic-framework-derived multi-heteroatom doped $\mathrm{Cu}_{1.8} \mathrm{Se} / \mathrm{C}$ composites for high-performance Na-ion hybrid capacitor. Sustain Mater Technol, 2021, 28: e00275

41 Peng Y, Chen Z, Zhang R, et al. Oxygen-containing functional groups regulating the carbon/electrolyte interfacial properties toward enhanced $\mathrm{K}^{+}$storage. Nano-Micro Lett, 2021, 13: 192

42 Moon S, Lee SM, Lim H-, et al. Relationship between multivalent cation charge carriers and organic solvents on nanoporous carbons in $4 \mathrm{~V}$ window magnesium ion supercapacitors. Adv Energy Mater, 2021, 11: 2101054

43 Lei H, Tu J, Tian D, et al. A nitrogen-doped graphene cathode for highcapacitance aluminum-ion hybrid supercapacitors. New J Chem, 2018, 42: 15684-15691

44 Duffin AM, Schwartz CP, England AH, et al. PH-dependent X-ray absorption spectra of aqueous boron oxides. J Chem Phys, 2011, 134: 154503

45 Kobayashi K, Hashimoto Y, Wang SL. Boron incorporation into precipitated calcium carbonates affected by aqueous $\mathrm{PH}$ and boron concentration. J Hazard Mater, 2020, 383: 121183

46 Fleet ME, Muthupari S. Boron K-edge XANES of borate and borosilicate minerals. Am Miner, 2000, 85: 1009-1021

47 Ni M, Huang Z, Lian Y, et al. Synergistic doping for pseudocapacitance sites in alkaline carbon supercapacitors. ChemElectroChem, 2018, 5: 84-92

48 Zhao Y, Wan J, Yao H, et al. Few-layer graphdiyne doped with sphybridized nitrogen atoms at acetylenic sites for oxygen reduction electrocatalysis. Nat Chem, 2018, 10: 924-931

49 Zhang LS, Liang XQ, Song WG, et al. Identification of the nitrogen species on $\mathrm{N}$-doped graphene layers and $\mathrm{Pt} / \mathrm{NG}$ composite catalyst for direct methanol fuel cell. Phys Chem Chem Phys, 2010, 12: 1205512059

50 Brodowski M, Kowalski M, Skwarecka M, et al. Highly selective impedimetric determination of haemophilus influenzae protein $\mathrm{D}$ using maze-like boron-doped carbon nanowall electrodes. Talanta, 2021, 221: 121623

51 Luo L, Zhou Y, Yan W, et al. Two-step synthesis of B and N co-doped porous carbon composites by microwave-assisted hydrothermal and pyrolysis process for supercapacitor application. Electrochim Acta, 2020, 360: 137010

52 Shao Y, Sun Z, Tian Z, et al. Regulating oxygen substituents with optimized redox activity in chemically reduced graphene oxide for aqueous Zn-ion hybrid capacitor. Adv Funct Mater, 2021, 31: 2007843

Acknowledgements This work was supported by the National Natural Science Foundation of China (51873198), the Engineering and Physical Sciences Research Council (EPSRC, EP/V027433/1), and the Royal Society (RGS\R1\211080).

Funding note Open Access funding provided thanks to the UK Read and Publish (Springer Compact) agreement.

Author contributions Li Y, Huang J, and He G performed the experiments and wrote the article. Kang L, Tian Z, Lai F, Brett DJL and Liu T helped to analyze the data and conceive the framework of this paper. All the authors commented on the final paper.

Conflict of interest The authors declare no conflicts of interest.
Supplementary information Experimental details and supporting information are available in the online version of the paper.

Open Access This article is licensed under a Creative Commons Attribution 4.0 International License, which permits use, sharing, adaptation, distribution and reproduction in any medium or format, as long as you give appropriate credit to the original author(s) and the source, provide a link to the Creative Commons licence, and indicate if changes were made.

The images or other third party material in this article are included in the article's Creative Commons licence, unless indicated otherwise in a credit line to the material. If material is not included in the article's Creative Commons licence and your intended use is not permitted by statutory regulation or exceeds the permitted use, you will need to obtain permission directly from the copyright holder.

To view a copy of this licence, visit http://creativecommons.org/licenses/ by/4.0/.

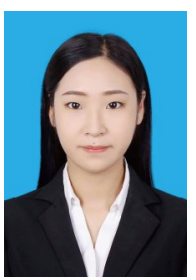

Yuying Li received her MSc degree from Zhengzhou University in 2021 and she is currently a $\mathrm{PhD}$ candidate at the Southeast University. Her research interest mainly focuses on the advanced electrode materials and charge storage mechanism for ZIBs and ZHSs.

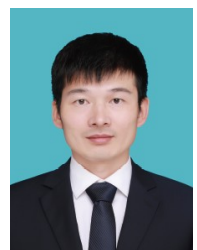

Jiajia Huang received his $\mathrm{PhD}$ degree in polymeric chemistry and physics from Sun Yat-Sen University in 2014. Currently, he is an associate professor at the School of Chemical Engineering, Zhengzhou University. His research focuses on functional polymers and carbon-based materials and their applications in adsorption separation of metal ions and electrochemical energy storage.

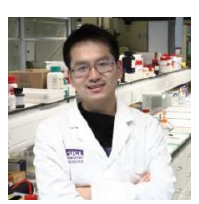

Guanjie $\mathrm{He}$ is an associate professor in materials chemistry, leader for the Advanced Functional Materials Research Group, University of Lincoln and an Honorary Lecturer of the University College London (UCL). Dr. He received his $\mathrm{PhD}$ in 2018 from the Department of Chemistry, UCL. His research focuses on materials for electrochemical energy storage and conversion applications, especially electrode materials in aqueous electrolyte systems.

\section{自组装杂原子掺杂碳纳米带作为超快充电锌离子混 合超级电容器阴极}

李钰莹 ${ }^{1}$, 黄佳佳 ${ }^{*}$, 六立群 ${ }^{2}$, 田志红 ${ }^{3}$, 赖飞立 ${ }^{4}$, Dan J.L. Brett ${ }^{2}$, 刘天西 ${ }^{5}$, 何冠杰 ${ }^{2,6^{*}}$

摘要 锌离子混合超级电容器(ZHSs) 由于其具有较高安全性, 较低成 本和超长寿命等优点, 适合应用于大型储能设备. 然而, 目前阴极材料 的倍率性能较差, 严重阻碍了ZHSs的发展. 基于此, 本文设计合成了一 系列自组装杂原子掺杂 $(\mathrm{B}, \mathrm{N}, \mathrm{O})$ 碳纳米带CPTHB-B $x$, 作为ZHSs的阴极 材料. 杂原子掺杂可以显著改善碳骨架的化学特性, 产生更多的活性位 点, 并加速电荷传输. 除此之外, 本文还证明了 $\mathrm{B}-\mathrm{N}$ 基团是快速吸附和 脱附锌离子的主要活性位点. 以CPTHB-B2作为阴极的ZHSs表现出最 优异的电化学性能, 在 $0.5 \mathrm{~A} \mathrm{~g}^{-1}$ 电流密度下, 比电容高达 $415.3 \mathrm{~F} \mathrm{~g}^{-1}$, 当 电流密度从 0.5 增大到 $100 \mathrm{~A} \mathrm{~g}^{-1}$ 时, 比电容保留率高达 $81 \%$, 能量密度 为 $131.9 \mathrm{~W} \mathrm{~h} \mathrm{~kg}^{-1}$, 功率密度为 $42.1 \mathrm{~kW} \mathrm{~kg}^{-1}$. 此研究为超快速锌离子存 储材料提供了新的设计思路. 